\title{
Executive control influences linguistic representations
}

\author{
Shiri Lev-Ari • Boaz Keysar
}

Published online: 9 August 2013

(C) Psychonomic Society, Inc. 2013

\begin{abstract}
Although it is known that words acquire their meanings partly from the contexts in which they are used, we proposed that the way in which words are processed can also influence their representation. We further propose that individual differences in the way that words are processed can consequently lead to individual differences in the way that they are represented. Specifically, we showed that executive control influences linguistic representations by influencing the coactivation of competing and reinforcing terms. Consequently, people with poorer executive control perceive the meanings of homonymous terms as being more similar to one another, and those of polysemous terms as being less similar to one another, than do people with better executive control. We also showed that bilinguals with poorer executive control experience greater cross-linguistic interference than do bilinguals with better executive control. These results have implications for theories of linguistic representation and language organization.
\end{abstract}

Keywords Psycholinguistics · Individual differences · Bilingualism

Language processing involves activation and suppression of information. During processing activation spreads to related items (e.g., Collins \& Loftus, 1975), and lexical access is achieved by suppression of competitors (e.g., La Heij, 1988). At the same time, people differ in how effective they are at suppression (e.g., Gernsbacher \& Faust, 1991) and activation (Cantor \& Engle, 1993). Since patterns of activation can influence linguistic representation by creating and changing associations and patterns of activation, variability in the way people process words, manage activation levels and create

S. Lev-Ari • B. Keysar

Department of Psychology, University of Chicago, Chicago, IL, USA

S. Lev-Ari $(\square)$

Laboratoire de Sciences Cognitives et Psycholinguistique,

ENS-CNRS-EHESS, 29 rue d'Ulm, Paris, France

e-mail: shirilevari@gmail.com associations might contribute to variability in the way people represent linguistic units. Here we investigate the role that executive function might play in shaping representation. We start by reviewing the role of executive control in language processing in general. We then spell out the specifics of our proposal, and finally we provide support for our claim by showing the role that executive control plays in language representation across languages among bilinguals (Exp. 1), as well as its role in representing the meanings of homonyms and polysemous words within a language (Exps. 2 and 3).

\section{The role of executive control in language selection among bilinguals}

Bilinguals must avoid mixing their languages when it is undesirable. According to D. W. Green's (1988) inhibitory control theory, one manner by which bilinguals achieve this goal is by employing language task schemas that control activation and inhibition levels during processing. These schemas can inhibit all lexical items that are associated with a specific language tag (D. W. Green, 1998). This inhibition is governed by the general executive control system. One type of evidence that is often used to support this model is that language switching is effortful, and more importantly, that switching back into the dominant language is more effortful than switching away from the dominant language to a subordinate one (Meuter \& Allport, 1999). Thus, when bilingual speakers name pictures in one of two languages, they are slowed down when they need to switch language, but they slow down even more if they switch from the subordinate language to the dominant one (Meuter \& Allport, 1999). This counterintuitive result is predicted by inhibitory models of language selection, such as D. W. Green's model, since they assume that the more dominant a language is, the more one has to inhibit it in order to use the subordinate one. Therefore, switching back to the dominant language is more difficult than switching back to a subordinate one, because doing so requires overcoming a greater level of inhibition. 
Others have suggested that cross-linguistic inhibition during language processing is purely local, and therefore restricted to the inhibition of competing lexical items, such as translation equivalents (e.g., Dijkstra \& van Heuven, 2002). Some of these accounts have also suggested that inhibition is reactive and automatic rather than active, and therefore might occur even when it is detrimental to performance (Colzato, Bajo, van den Wildenberg, Paolieri, Nieuwenhuis, La Heij and Hommel 2008; Treccani, Argyri, Sorace, \& Della Sala, 2009). For example, bilinguals show a greater attentional blink: When two targets appear rapidly separated by a few distractors, bilinguals are less able to detect the second target, presumably because of their automatic reactive inhibition of the distractors following the first target (Colzato et al., 2008).

Additional indirect support for the role of executive control in language selection has come from evidence that bilinguals have better executive control than do monolinguals, especially in tasks that require attention to one cue while ignoring a competing cue (Bialystok \& Craik, 2010). For example, monolinguals take longer to determine the direction in which a target is pointing when it is placed between flankers that point in an incongruent direction, as compared to between flankers in the congruent direction, but bilinguals are less influenced by such surrounding flankers (Costa, Hernández, \& Sebastián-Gallés, 2008). The source of this bilingual advantage is stipulated to result from bilinguals' need to constantly control their languages by inhibiting the languages not in use. Such constant use of executive control may improve it, leading to superior control mechanisms. This is consistent with evidence that frequently practicing one's control system - for instance, by playing video games - improves one's attentional control (C. S. Green \& Bavelier, 2003).

A few recent studies (Festman, Rodriguez-Fornells, \& Münte, 2010; Gollan, Sandoval, \& Salmon, 2011; Linck, Schwieter, \& Sunderman, 2012) have directly linked executive function and language selection. Gollan et al. tested bilinguals on both the flanker task and a verbal fluency task, in which participants name as many words as possible that follow some criterion. Gollan et al. then examined the relation between the degree to which a participant was distracted by the incongruent flankers and the frequency of intrusions from the irrelevant language in the verbal fluency task. As predicted, the number of overall intrusions from the irrelevant language was predicted by participants' performance on the flanker task. In contrast, errors on the verbal fluency task that are not related to crosslinguistic intrusion were not associated with performance on the flanker task suggesting that better performance on the flanker task was not simply because participants who are better on one task might be better on other tasks.

At the same time, the inhibition of the language not in use is rarely complete. Several studies employing diverse tasks and measures have shown that even when bilinguals perform a task in a single language, the language not in use is still activated.
For example, Russian-English speakers are more likely to be distracted by a stamp, called marka in Russian, than by an unrelated control object when asked to move a marker, even when they perform the task exclusively in English (Spivey \& Marian, 1999). Likewise, they are more likely to look at the marker, called flomaster in Russian, than at an unrelated control object when they are asked to move the stamp (marka) in a task carried out exclusively in Russian (Spivey \& Marian, 1999). Similarly, Chinese-English bilinguals show reduced N400s when they read or hear pairs of English words whose translation equivalents in Chinese share a sound, as compared to pairs of English words whose translation equivalents in Chinese do not share a sound. This occurs despite the fact that the task is solely in English (Wu \& Thierry, 2010). In general, then, evidence suggests that bilinguals rely on executive function to control language selection and to minimize crosslinguistic interference, but also that the inhibited linguistic items are often still activated to some degree.

\section{The role of executive control in the lexical access of ambiguous words}

Executive control is integral to language processing in general. For example, most evidence suggests that when people read or hear a homonym, its dominant meaning is automatically activated, and if inappropriate, is later suppressed (e.g., Gernsbacher, Varner, \& Faust, 1990; Giora, 2003). So, even if the context involves a river, the word bank activates its financial institution meaning, which is then suppressed.

In contrast to homonyms, suppression is less relevant for the processing of polysemous words, especially those whose meanings are highly similar to one another. Whereas the meanings of homonyms are mutually exclusive, compete with one another, and therefore require suppression, the meanings of polysemous words are related and can often support each other (Beretta, Fiorentino, \& Poeppel, 2005). This is consistent with the finding that, whereas homonyms are processed more slowly than unambiguous words, polysemous words are processed at the same speed as, and often faster than, unambiguous words (Beretta et al., 2005; Frazier \& Rayner, 1990; Klepousniotou \& Baum, 2007; Rodd, Gaskell, \& Marslen-Wilson, 2002). Magnetoencephalography studies examining the latency of the M350, a component reflecting lexical activation, have similarly shown that polysemy leads to a reduction in M350 latencies in the left hemisphere, whereas homonymy leads to increased M350 latencies (Beretta et al., 2005; Pylkkãnen, Llinás, \& Murphy, 2006). The event-related potential N400 component, which reflects semantic integration, also shows a reduction only in the contextually relevant meaning for homonyms, but a reduction for all senses of polysemous terms, further supporting that all senses of polysemous terms are simultaneously coactivated and support, rather than inhibit, 
one another (Klepousniotou, Pike, Steinhauer, \& Gracco, 2012). Furthermore, words that overlap in their meanings, such as head and skull, prime one another (Finkbeiner, Forster, Nicol, \& Nakamura, 2004). This suggests that even when related senses have distinct lexical entries, they might prime and facilitate processing of each other. Because executive function is also associated with increased activation of relevant items (Cantor \& Engle, 1993), people who have better inhibitory skill might also be those who activate related meanings the most. For example, readers with higher working memory are more likely than readers with lower working memory to inhibit the irrelevant meanings of ambiguous words, as well as more likely to show priming for subordinate meanings of homonyms when these are context-relevant (Gadsby, Arnott, \& Copland, 2008). That is, people with better executive control are often better both at inhibiting distracting information and priming and retrieving relevant information.

\section{Executive control and linguistic representation}

In general, people differ in their executive control. Because executive control is integral to language processing, the efficacy of executive control influences the efficiency and success of language processing (Gernsbacher \& Robertson, 1995). We propose that such differences in processing can ultimately influence language representation. Specifically, we propose that the coactivation that results from poor inhibition ultimately influences the meaning of linguistic units.

Consider the following example, in the context of bilingualism, as an illustration of our proposal. In English, the verb play can describe engagement both in games and with musical instruments. In contrast, Hebrew has two distinct words to refer to these activities. Every time a Hebrew-English bilingual processes the word play in English, both Hebrew translation equivalents might be activated and then the irrelevant one would need to be suppressed. The poorer the bilingual's executive control is, the less successful the suppression would be, and therefore the greater the activation of the irrelevant Hebrew word would be. Such activation in contexts that are inappropriate for the Hebrew word can ultimately transform the meaning of the word by integrating such contexts into its meaning. That means that even though playing an instrument and playing a game have little to do with each other for Hebrew monolinguals, the two meanings might start to overlap for Hebrew-English bilinguals, and, crucially, that this would be more pronounced the poorer their executive control is. In general, learning a second language influences one's first language. A common influence is the use of words in the first language in inappropriate contexts, because the translation equivalents are used in that way in the second language (Cook, 2003). We propose that the extent of this influence critically depends on executive control.
In the context of bilingualism, Degani, Prior, and Tokowicz (2011) proposed a coactivation model, which postulates that coactivation leads to the creation of associations between the coactivated words. Here we build on their ideas and extend them in two important ways. First, we argue that the impact of coactivation depends on executive control. Second, we show that the same pattern holds not only across languages, but also with ambiguity within a language.

We began the investigation of this idea by looking at perceived similarity. When two items share a label, speakers perceive them to be more similar to one another (Jiang, 2000). For example, English speakers who have learned Hebrew as a second language rate English words, such as tablecloth and map, which share a label in Hebrew but not in English, as being more similar to one another than do English speakers who do not speak Hebrew. Furthermore, Hebrew language learners do so even when they rate the words in English, without Hebrew being mentioned (Degani et al., 2011). Evidence from event-related-potential paradigms has similarly shown that, at least for bilinguals with lower proficiency, the context-irrelevant homonymous meaning of translation equivalents interferes during processing in a second language (Elston-Güttler \& Friederici, 2005). Behavioral data with polysemous terms has suggested that polysemy can interfere even when bilinguals are highly proficient (Elston-Güttler \& Williams, 2008). According to our proposal, such an impact of the irrelevant language depends on executive control: The poorer bilinguals' executive control, the less successful they are at inhibiting the language not in use. This would result in greater coactivation, which would lead to greater influence of the languages over one another. In cases in which translation equivalents differ in their uses and meanings, the greater coactivation that results from poorer executive control might lead to a widening of the narrower term, and consequently to greater perceived similarity of the two meanings. For example, among bilinguals with poor executive control, the narrower Hebrew term for playing a game would be coactivated with the broader English meaning, which includes playing games as well as instruments. Consequently, the Hebrew word might start encompassing the meaning of playing an instrument, making the two separate Hebrew terms for playing games and for playing instruments seem more similar.

A similar increase in the perceived similarity of meaning due to insufficient inhibition can occur within a language, as well. For example, whenever an English speaker processes the word trunk as meaning a "tree trunk," the meanings of "elephant trunk" and "car trunk" need to be suppressed. If we are correct, the poorer one's executive control, the less successful the suppression of these meanings, and therefore the higher would be their coactivation in irrelevant contexts. Such coactivation can lead to greater perceived similarity of the various meanings. 
Next, we will describe our tests of this proposal by evaluating the relation between executive control and crosslinguistic influence on linguistic representation, intralinguistic representation of ambiguous words, and learning ambiguous words in a novel artificial language.

\section{Experiment 1}

In Experiment 1, we tested whether bilinguals' executive control influences the degree to which they experience crosslinguistic interference. The experiment tested our proposal that the better the bilinguals' executive control, the less their two languages should influence one another. In other words, the better a bilingual's executive control, the more differently that person should perform in the two languages. When such a bilingual processes two concepts in a language in which the concepts share a label, he or she would find them to be more similar to one another than they would be when processed in a language in which they do not share a label. Poorer executive control, in contrast, would lead to greater coactivation of the concepts from the two languages, and consequently to their increased similarity in meaning. Since we propose that for a bilingual with poor executive control both languages are activated at all times, that bilingual should be guided by the same linguistic frames and perform similarly in both languages. Therefore, when the user's executive control is poor, the degree to which two concepts that share a label in only one language would seem similar should not depend on the language in use.

To test this proposal, Hebrew-English bilinguals rated the similarity of pairs of unlabeled pictures that shared a label in only one of their languages. For instance, "closet" and "coffin" share the label aron in Hebrew, and a "house key" and a "computer keyboard key" share the label key in English but have different labels in Hebrew, mafte'ach and makash. The bilinguals performed the rating task twice, at least a week apart: once after receiving the instructions in Hebrew, and once after receiving instructions in English. We examined whether working memory, a measure of executive control (Kane, Conway, Hambrick, \& Engle, 2007), would predict the degree to which their similarity ratings would be influenced by the language of the session. That is, we examined whether working memory predicted the degree to which the similarity ratings of unlabeled objects that share a label in Hebrew (e.g., a closet and a coffin) would be higher when the instructions were in Hebrew rather than in English, as well as the degree to which the similarity ratings of the objects that share a label in English (e.g., two types of "key") would be higher when the instructions were in English rather than Hebrew. We predicted that higher working memory would allow users to separate the languages more, leading to more language-specific representations, and therefore greater difference in the similarity ratings between the two sessions.
Method

\section{Participants}

A group of 47 Hebrew-English bilinguals participated in the study. The majority were late bilinguals, who had been raised in Israel and moved to the United States as adults. ${ }^{1}$ Their ages ranged between 22 and $46(M=31.8, S D=5.1)$, and the large majority of them $(N=39)$ started learning English in the fourth grade and reported using both Hebrew and English on a daily basis.

\section{Stimuli}

We compiled a list of pairs of concepts that share a label in either Hebrew or English, but not both. We collected pictures to represent each concept and pretested them to make sure that they represented the intended concepts, as indicated by labeling a picture with the target ambiguous term in the relevant language and its translation equivalent in the other. We presented the pictures to a different group of HebrewEnglish bilinguals, who did not participate in the experiment, and asked them to describe the content of each picture with a word or a short sentence. These pretest sessions were either entirely in Hebrew or entirely in English. We had a total of 13 responses in English and 11 responses in Hebrew. On the basis of the pretest, we selected pictures that had at least $70 \%$ agreement. In all, 26 pairs passed the pretest: 15 pairs of concepts that share a label in Hebrew but not in English, and 11 pairs of concepts that share a label in English but not in Hebrew (see Appendix A). ${ }^{2}$ Some pairs represented nouns, such as a house key and a keyboard key or a closet and a coffin, and others represented verbs, such as playing a game and playing an instrument, or vacuuming and drawing water, which both translate to lish'ov in Hebrew. Fifty additional pairs of pictures were added as fillers. Half of the pairs were similar to one another, such as two different cups of coffee, whereas the other half were very different from one another, such as a hammer and a pile of towels.

\section{Procedure}

Participants completed two sessions, at least a week apart, each with multiple tasks. Some performed the Hebrew session first $(N=29)$ and some performed the English session first $(N=18)$. The Verbal Working Memory task was always

\footnotetext{
${ }^{1}$ However, three of the participants had English as a first language; one had Russian as a native language, Hebrew as a second language, and English as a third language; and two were simultaneous bilinguals. Additionally, one had moved to the United States in his early teens, and another participant had spent a few years in the United States as a child.

${ }^{2}$ Pictures of the stimuli can be supplied upon request.
} 
the first task in the English session, and the picture similarity was the last task in both sessions. The session in English was conducted by a native speaker of English who does not speak any Hebrew. The session in Hebrew was conducted by a native speaker of Hebrew. All conversation, tasks and forms were exclusively in the designated language of the session.

Verbal working memory task We used a standard verbal working memory task (Unsworth, Heitz, Schrock, \& Engle, 2005). Participants determined whether sentences were sensible and received a letter for memorization after each sentence. After each set of sentences and letters, which ranged in length from three to seven, participants were asked to recall the letters they had memorized in the order they received them. Participants' working memory score was calculated as the number of letters they recalled in the correct order. By requiring participants to alternate two different tasks, this task measures working memory rather than simply memory span. We chose to use a working memory measure, because working memory is a measure of executive control (Kane et al., 2007), and has been shown to predict performance on different types of inhibition tasks (e.g., Aslan \& Bäuml, 2011; Kane \& Engle, 2003; Rosen \& Engle, 1998). Since no standard version of this task exists in Hebrew, and because linguistic differences between Hebrew and English prevent a simple translation of the task into Hebrew, we tested participants' working memory in English.

Picture similarity Participants saw pairs of unlabeled pictures on the screen. They were asked to rate the similarity of what is shown in the pictures by pressing a number between 1 and 7 , with 1 representing Not similar at all and 7 representing Very similar.

\section{Results}

In general, participants rated pairs of unlabeled pictures as being more similar to one another when the shared label was in the language of the session than when it was in the sessionirrelevant language (shared-in-session language, $M=3.91$, $S D=0.81$; non-shared-in-session language, $M=3.74, S D=$ $0.91), t(25)=2.7, p<.02$. This suggests that in general, bilinguals' representations are affected by the language context. To test whether working memory predicted the degree to which bilinguals' representations were language-specific, we first calculated participants' "language specificity" score. This was calculated as the difference between the $z$-scored ratings when the label matched in the session's language (e.g., a house key and a computer key in the English session, a coffin and a closet in the Hebrew session) and when the label did not match the session's language (e.g., a house key and a computer key in the Hebrew session, a coffin and a closet in the English session). We then ran a regression with working memory score as the predictor and language specificity score as the dependent measure. Working memory scores ranged from 4 to $75(M=48.7, S D=15.9)$. Working memory significantly predicted the degree to which participants' performance was language-specific, such that higher working memory was associated with more languagespecific performance $\left(R^{2}=.11, p<.03\right)$ (see Fig. 1).

In order to make sure that the regression results were not driven by influential outliers, we calculated Cook's distance for all data points. Three data points had values higher than $4 / n(0.085$, for this data set), and therefore might have unduly influenced the results (these participants had working memory capacity of 40,55 , and 60 ). Removing each of these data points did not change the direction or significance of the effect that we reported (all $p \mathrm{~s}<.03$ ).

It is important to note that the relation between working memory and language-specific performance cannot be explained by a simple correlation between working memory and reliance on lexical labels, ability to note similarity, or differences or changes in interpretations of similarity. This is because our dependent measure was not the absolute similarity rating, but the degree to which the rating was influenced by the linguistic context. In order for participants to receive a high language specificity score, they needed to rate the items as being more similar to one another when the language context was the one in which the depicted items shared a label, as well as to rate their similarity as being lower when the language context was not the one in which they shared a label. This would reduce the consistency of ratings across language contexts. In our results, those with lower working memory exhibited greater consistency in their ratings across language contexts, whereas those with higher working memory were less consistent across conditions.

It is possible, though, that even though participants rated the similarity of unlabeled pictures, implicitly they generated labels for the pictures in the language of the session, and relied on those labels in their judgments. Although this on its own cannot explain our pattern of results, it could provide an alternative account if one were also to assume that executive control influences the likelihood of implicit naming or reliance on the labels. For example, individuals with higher executive control might be more likely to implicitly name objects and to rely on the lexical labels, due to their better verbal abilities. If this is true, then implicit labeling could explain the more languagespecific performance of participants with higher executive control, as compared with the performance of those with lower executive control, which was more consistent across language contexts. Due to this possibility that our results could reflect differential availability of labels, they cannot unambiguously reflect differences in conceptual representation as a function of executive function. Experiments 2 and 3 were designed to rule out such an alternative explanation. 


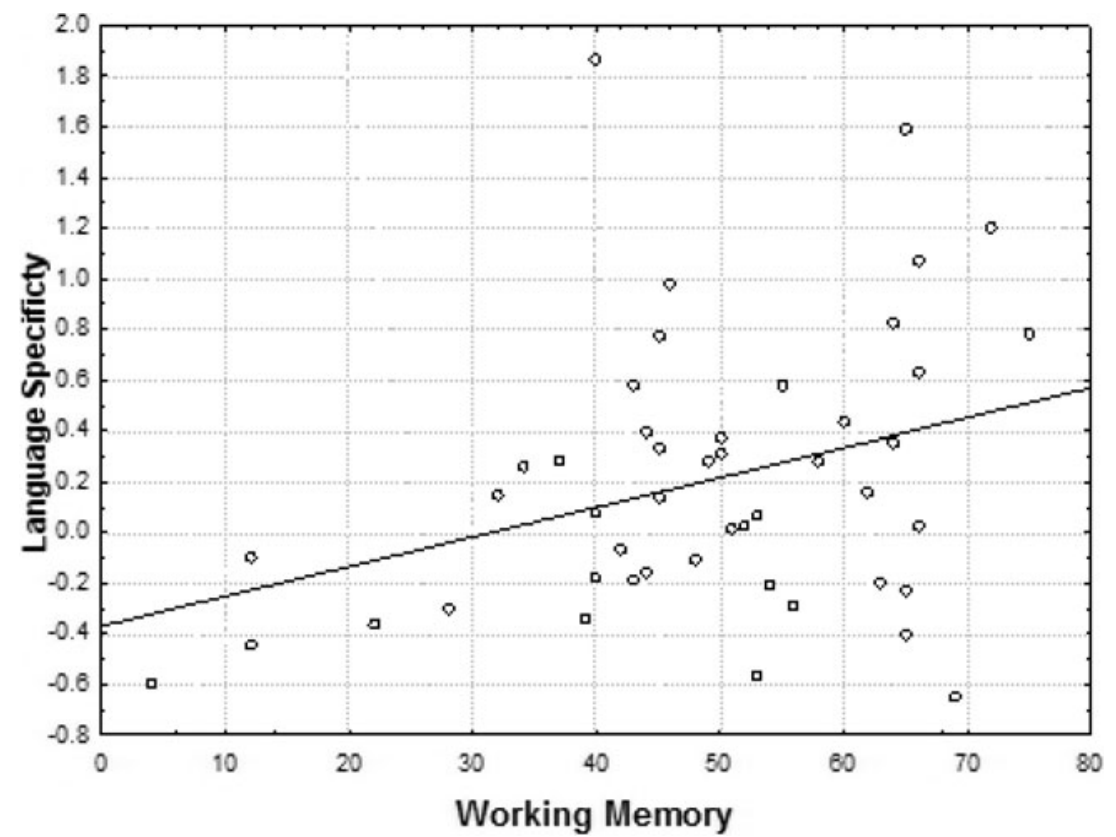

Fig. 1 Degrees to which participants' performance was influenced by the language of the session in Experiment 1, as a function of their working memory

Another potential concern could be that bilinguals performed the executive function task in English, the less dominant language of most of the participants. Therefore, it could be that the bilinguals' working memory scores were influenced by proficiency. It is important to note, though, that all participants were residing in the United States at the time, and the majority of them were pursuing an advanced degree at an English-speaking university. All participants were therefore proficient in English. Furthermore, in another set of studies, Lev-Ari and Peperkamp (2013) have shown that bilinguals' inhibitory skill, which was measured in participants' first and dominant language, predicted the degree to which their second language influenced their first language. It is therefore unlikely that the relation between executive function and language-specific manner of thinking that we found here would be driven by differences in proficiency.

Similarly, it is worth noting that participants were probably aware that the fact that they were bilinguals was relevant for the study, as they were told that there would be two sessions, one in Hebrew and one in English. At the same time, none of the participants was aware of the specific goals or hypotheses of the experiment, or even that it related to cross-linguistic interference in general.

Finally, one might wonder about the influence of the first language on the second language versus the influence of a second language on the first, as well as about the role of the languages' relative dominance. Since the majority of our participants were Hebrew dominant, it was not possible to assess the relative contributions of direction of influence while controlling for session order and level of executive control. In general, however, our account predicts that poorer executive control should lead to greater coactivation of the two languages during both first and second language processing. Evidence has indicated that speakers need to exercise greater effort to inhibit their first language (e.g., Meuter \& Allport, 1999), suggesting that there might be greater activation of the first language during second language processing. Yet the resting level of a language, and therefore the degree of required inhibition, also depends on frequency and context of use, as well as on language context. It therefore might differ among individuals with different experiences or even within individuals across contexts. In general, both directions of influence are evidenced in the literature (e.g., Cook, 2003; Odlin, 1989).

Experiment 1, then, was in line with our proposal that bilinguals' executive control predicts the degree to which their performance is language-specific, and therefore the degree to which representations in their two languages would be influenced by one another. The results of this experiment suggest that the better that bilinguals' executive control is, the more differently they think in their two languages, and the less consistent is their performance across languages. Whereas these results are consistent with our proposal regarding representation, we could not rule out the possibility that they might reflect processing that involved implicit labeling, and not differences in representation. Experiments 2 and 3 would provide less ambiguous support for our general claim regarding executive control and language representation.

\section{Experiment 2}

In Experiment 1, we investigated our proposal that executive control influences linguistic representations across the 
languages of bilinguals. In Experiment 2, we investigated the influence of executive control on linguistic representations within a language. Similarly to the way that the coactivation of translation equivalents influences their perceived similarity, coactivation of the different meanings of ambiguous words could influence their perceived similarity. Specifically, we proposed that the different meanings of homonyms might seem less similar to one another, the better that one's executive control was, because successful processing of homonyms requires the inhibition of the irrelevant meanings. In contrast, executive control might relate differently to the perceived similarity of polysemous words. Unlike homonyms, the different meanings of polysemous words, especially highly similar ones, might prime and strengthen one another (Beretta, Fiorentino, \& Poeppel, 2005; Klepousniotou \& Baum, 2007; Rodd et al., 2002). Although some studies have found similar inhibition across the meanings of homonymous and polysemous words (Kelin \& Murphy, 2001), others have shown that the degree of inhibition depends on how similar the meanings of homonyms and polysemous words are. Particularly, the subordinate meanings of polysemous words whose meanings are very similar facilitate, rather than inhibit, access to the dominant meaning of the polysemous word, whereas inhibition was found for homonyms and polysemous words with only medium similarity among their meanings (Klepousniotou, Titone, \& Romero, 2008). Therefore, executive control might not influence the representation of polysemous words with very similar meanings. At the same time, executive control has been shown to be associated with greater activation when activation is beneficial (Gadsby, Arnott, \& Copland, 2008; Rosen \& Engle, 1998). Therefore, when processing polysemous words, people with better executive control might activate their related meanings to a greater degree than people with poorer executive control, and this could lead to greater perceived similarity.

To test whether executive control influences the perceived similarity of ambiguous words, we tested native English speakers with the same picture similarity task from Experiment 1 , and examined whether their similarity ratings for the pictures that shared a label in English would be predicted by their inhibitory skill.

In Experiment 1, we used the verbal working memory task to measure executive control. Whereas working memory tasks are a standard measure of executive control, lexical access is thought to be specifically guided by an inhibitory mechanism (e.g., Anderson, Bjork, \& Bjork, 1994), one component of executive control. In Experiment 2, we thus used a more direct measure of inhibition, the retrieval-induced inhibition task, also known as the retrieval-induced forgetting task (Anderson et al., 1994). This task measures the degree of inhibition that is exercised during lexical access, thus ensuring that we were measuring the most relevant component of executive function to control patterns of activation and inhibition during language processing. It should also be noted that the tasks that we used to evaluate executive control in Experiments 1 and 2 were closely related, as the working memory task that we used predicts performance on the retrieval-induced inhibition task (Aslan \& Bäuml, 2011). In the retrieval-induced inhibition task, participants first memorize words from a few categories, and then they are presented retrieval cues and retrieve half of the words from some of the categories. Other categories are not practiced at all, and serve as a control. The last stage is a memory test on all memorized words. Inhibition is calculated as the ratio between the median recognition latency of the nonpracticed words from the practiced categories and the median recognition latency of the control words. Both of these types of words had not been practiced; therefore, any added difficulty in retrieving the nonpracticed items from the practiced categories could be interpreted as resulting from inhibition of those items during the retrieval practice. If inhibitory skill influences the representation of ambiguous words, then higher inhibition should be associated with lower similarity ratings for pictures that represent the different meanings of homonyms. In contrast, for pictures representing the different meanings of polysemous words, higher inhibition should not be associated with similarity ratings, or it might even be positively associated with it.

Recall the alternative explanation for Experiment 1's results, which assumed that people with higher executive control rely more on implicit labeling when they assess conceptual similarity. If this is true, it would predict the same pattern of results for homonyms and polysemous words. According to this account, those with higher executive control should judge both homonyms and polysemous words as being more similar to each other than would individuals with lower executive control. Our proposal makes the same prediction for polysemous terms, but the opposite one for homonyms.

Method

\section{Participants}

A group of 50 native speakers of English participated in the study for pay or credit.

\section{Stimuli}

Retrieval-induced inhibition task Six words were selected for each of three categories: animals, vegetables, and occupations. All of the words were common words, such as lion and teacher. No two words in the same category started with the same letter. Each category was divided into two lists of three words, and then six versions were created for the practice stage by combining each of the lists in a category with one 
of the lists in each of the other categories. Therefore, a sixth of the participants practiced half of the animal words and half of the vegetable words, another sixth of the participants practiced the other half of the animal words and the other half of the vegetable words, another sixth of the participants practiced half of the animal words and half of the occupation words, and so on. Eighteen more words that were never studied — six from each of the studied categories - served as fillers in the final recognition task.

Picture similarity task All of the stimuli from Experiment 1 were used in Experiment 2. Since only half of the experimental items from Experiment 1 were relevant for the native English speakers, we compiled a list of additional ambiguous words and pretested pictures representing them to make sure that they represented the intended concept, in a manner similar to the pretest in Experiment 1. We selected pictures for which at least $70 \%$ of all pretest respondents provided the intended labels. Nine pairs of pictures passed this criterion and were added to the pairs from Experiment 1 (see Appendix A).

\section{Procedure}

Participants performed the retrieval-induced inhibition task, followed by the picture similarity task.

Retrieval-induced inhibition task The procedure was based on that of Veling and van Knippenberg (2004). Participants memorized 18 words for a later recall. Each word appeared on the screen next to its category name- for example, "ANIMALStiger." The words were presented blocked by category, with the order of categories as well as category items randomized. Items appeared for $5 \mathrm{~s}$ each, with a 1 -s interval between items.

Next, participants performed a cued recall test. The cues were the category name followed by the first letter of the word - for example, "ANIMALS-t." Only one studied item fit each cue. Participants typed the responses on the computer. They were asked to recall only six out of the 18 words - half of the items in two of the categories, and none of the items from the third category. The practiced categories, as well as the selection of items to be practiced, were counterbalanced across participants. Participants were asked to recall each of these items three times. Thus, a third of the items were practiced, a third of the items were not practiced but belonged to the practiced categories ("inhibited"), and a third of the items were not practiced and belonged to the nonpracticed category ("control").

Following the practice stage, participants were presented with all of the learned items as well as an equal number of new items, and judged whether each item was on the study list as quickly as possible. We measured response times and calculated inhibition as the proportion of the median response time to the inhibited items to the median response time to the control items. Since neither type of words was practiced, longer response times to the inhibited words would reflect retrieval difficulty due to inhibition during the cued retrieval stage.

Picture similarity task The procedure was identical to that of Experiment 1.

During debriefing, participants were probed to see whether they noticed the existence of pairs of pictures that shared an ambiguous label.

\section{Results}

Participants' inhibitory skill scores ranged from 0.62 to 1.53 $(M=1.09, S D=0.22)$. Fifteen of the participants reported noticing the existence of the pairs of pictures sharing an ambiguous label, but none saw a relation between the picture similarity task and the retrieval-induced inhibition task. To be conservative, we will report analyses on the remaining 35 participants, but all effects remained the same if those 15 participants were included.

In order to test whether inhibitory skill influences perceived similarity of the referents of ambiguous words differently for homonyms and polysemous words, we first needed to determine how homonymous or polysemous each term is. The difference between polysemous and homonymous words is not categorical, but a continuum that extends from clearly homonymous terms to clearly polysemous terms, with many terms falling in between (Tuggy, 1993), and location on the polysemy continuum determines the degree to which inhibition is required in processing (Klepousniotou, Titone and Romero 2008). To determine where the specific terms fell on the continuum, we $z$-scored each participant's rating and then calculated the average $z$-scored rating that each pair of referents for ambiguous terms received across all participants, and entered that as a predictor in our analysis. Pairs that received a high similarity rating on average were closer to being polysemous, whereas pairs that received a very low similarity rating on average were closer to being homonymous.

We then ran a mixed-model regression with subjects and items as random variables and inhibitory skill, similarity, and their interaction as fixed effects. We included both intercepts and a slope for item similarity for the random variables. ${ }^{3}$ The dependent measure was the similarity ratings, $z$-scored by participants. This analysis yielded the predicted interaction between inhibitory skill and similarity $(\beta=0.62, S D=0.26$, $t=2.4$; See Appendix $C$ for the full results). In general, the interaction showed that the more polysemous a concept was on the continuum, the more that inhibitory skill led to greater

\footnotetext{
${ }^{3}$ In this and all further analyses, we tested for the significance of each slope by comparing a model with the slope to a model without it by means of a likelihood ratio test, and we included all slopes that improved the model (Baayen, 2008, p. 275) without leading to overparameterization (Jaeger, 2008).
} 
similarity rating for it, and vice versa. In order to examine more closely the role of inhibitory skill in influencing the perceived similarity of words that were more clearly either homonyms or polysemous, we identified items as being more clearly homonyms if their average $z$-scored rating was at least half a standard deviation below the average rating, and as being more clearly polysemous if their average $z$-scored rating was at least half a standard deviation above average. Six items were categorized as being clearly homonyms (trunk, bar, bat, nail, key, and table), and three as being polysemous (bag, arrow, and fan). A separate analysis on the homonymous items revealed a negative, though nonsignificant, association between inhibitory skill and similarity rating $(\beta=-0.36, S D=0.33, t<2)$, suggesting a tendency for higher inhibitory skill to be associated with lower similarity rating for the referents of homonymous terms. A similar analysis on the polysemous revealed a significant positive association between inhibitory skill and similarity rating ( $\beta=0.73, S D=0.28, t=2.63$; see Fig. 2$)$ : The higher participants' inhibitory skill, the more similar they judged the referents of polysemous words to be.

Our hypothesis was that inhibitory skill would predict the similarity ratings of pairs of referents of ambiguous terms because of the need to inhibit competing items during processing. The complement of this hypothesis was that inhibitory skill would not predict the similarity ratings of items that did not compete with each other during processing. We evaluated this in two ways. First, we examined whether inhibitory skill predicted the similarity ratings of the fillers. The results clearly showed that it did not, $\beta=-0.04, t<1$. For an even stronger test, we evaluated whether inhibitory skill predicted the similarity ratings of pictures that share a potential label in Hebrew, and therefore are ambiguous in Hebrew. These items were fillers in Experiment 2, but experimental items in Experiment 1. Although these items had exhibited a sensitivity to level of inhibitory skill in Experiment 1 , their ratings were not related to inhibitory skill in Experiment 2, in which participants did not speak Hebrew, $\beta=0.18, t<2$. This strengthens the idea that the effect in Experiment 1 was due to knowledge of the language, as opposed to an element of the pictures.

This analysis suggests that inhibitory skill indeed influences the representation of linguistic units. It also shows that the role of inhibitory skill is different for different types of words.

The alternative account that assumes a role for implicit labeling predicts that high-executive-function individuals would perceive higher similarity for both polysemous and homonymous words. The differential effect for homonyms and polysemous terms strongly indicates that the effect that we found was not due to implicit reliance on labeling, nor to a third factor correlating with executive control.

Though these results are in line with our predictions, the classification of items into homonyms and polysemous words

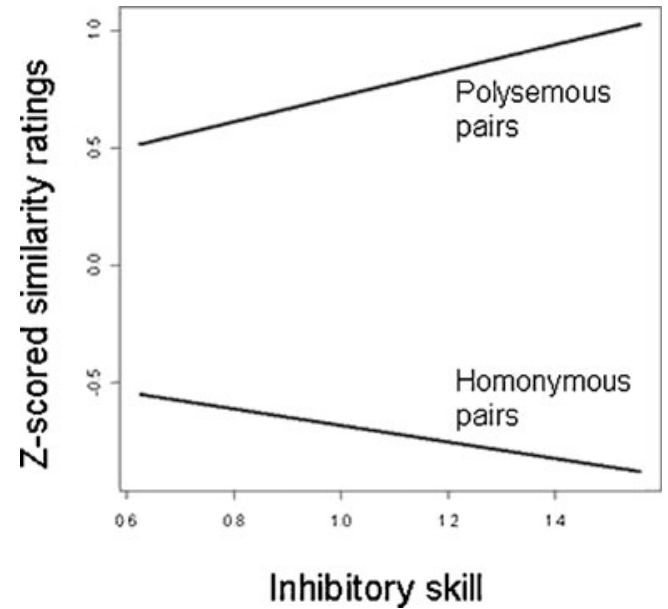

Fig. 2 Perceived similarity of the referents of ambiguous terms in Experiment 2, measured by $z$-scored ratings of picture pairs as a function of inhibitory skill and ambiguity type. See the Method section for details on the way that inhibitory skill was measured

was done on the basis of participants' ratings, and only a subgroup of the items seem to have been clearly homonymous or polysemous, whereas others fell in between. Additionally, the classification into ambiguity types did not control for other potential differences between the items, such as frequency. Therefore, to ensure that these results were not spurious or driven by other factors, we conducted Experiment 3, in which we taught participants a novel "language" for novel concepts. This language included clearly polysemous and homonymous terms. Thus, we were able to test the role of inhibitory skill in influencing the perceived similarity of ambiguous terms while controlling for confounding variables that could exist in a natural language and with natural objects.

\section{Experiment 3}

Experiment 3 further tested the proposal that inhibitory skill influences the perceived similarity of the meanings of ambiguous terms, and that it influences perceived similarity differently for polysemous and homonymous words. Since only polysemous words whose meanings are highly similar to one another seem to show facilitation (Klepousniotou et al., 2008), we focused on a particular type of polysemy: polysemous words whose meanings belong to the same category. The relations between the meanings of polysemous words could be of different types, yet the items in Klepousniotou et al. (2008) that were rated as having highly similar meanings seem to have had meanings that fell into the same category. The same was true for the words in Experiment 2 that were categorized as being polysemous. We therefore followed this model for the items in Experiment 3. We created novel "objects" and invented a novel "language" for them. We used novel objects in order to prevent participants from using 
English terminology, and to prevent them from relying on associations for existing objects. The novel objects that we invented fell into one of four clear categories. Thus, we could manipulate ambiguity type by manipulating whether the objects that shared a label belonged to the same category, and therefore would have related meanings, or to different categories, and therefore would have unrelated meanings. Different types of relations are possible between the senses of polysemous words. For example, some senses have a metonymic relation, whereas others are analogical extensions of meaning to similar entities or actions. The meanings of homonyms tend to be unrelated and often belong to two different categories (e.g., the animal bat and a baseball bat). The senses of polysemous words, in contrast, often belong to the same category. For example, both a paper fan and an electric fan are tools used to blow air. At the same time, other members of this category, such as an air conditioner, have a different name. The new language that we created exploited these relations by providing identical labels to two novel objects, either from two different categories or from the same category.

We created the following four categories: a grid with patterns of red dots, arrays of lines, arrays of cubes, and novel shapes (see Appendix B). Each category had six members. Two members of each category shared a label (polysemous words), and another member shared a label with a member in one of the other categories (a homonym). After participants had learned the language, they performed a picture similarity task, which was similar to the picture similarity tasks in Experiments 1 and 2, except that all judged items were the novel objects. We measured whether participants' inhibitory skill predicted the perceived similarity of the referents sharing a homonymous and a polysemous label.

\section{Method}

\section{Participants}

A group of 141 native English speakers participated for pay or for credit.

\section{Stimuli}

Retrieval-induced inhibition task We used the same stimuli as in Experiment 2.

Artificial language We created four categories, shown in Appendix B, and generated six novel members for each of the categories. Eighteen labels were generated by changing one letter in frequent English words. All of the resulting labels were legal strings in English. Labels were mapped onto category members such that two members in each category shared a label, and one member from each category shared a label with another member in a different category. We created a second version in order to unconfound labels and category members, such that the three members in each category that shared a label with another member in the first version did not share a label with any other item in this version, and those that had distinct names in the first version shared a label in this second version.

\section{Procedure}

Participants first performed the retrieval-induced inhibition task. Afterward, they learned the artificial language, and finally, they performed the similarity-rating task.

Retrieval-induced inhibition task We used the same procedure as in Experiment 2.

Learning the artificial language Participants were presented with the new novel images and names and were instructed to memorize them. They saw each novel item on the screen, with its name below, and said the name out loud. The item and the name stayed on the screen for $4 \mathrm{~s}$, and then they were replaced with a new novel item and name. Each item appeared in this manner three times and in a random order.

Next, participants practiced labeling the images from memory in eight rounds. Each of the images appeared on the screen unlabeled, in a random order, and participants attempted to recall and type its label. If participants responded correctly, they received another image. If not, the correct label appeared on the screen for $3 \mathrm{~s}$, and participants were asked to say it out loud. In that case, the image appeared again later in the same round until participants provided the correct label for it. Once participants had responded correctly to all 24 items, they started a new round of practice in which they practiced the same 24 items again in the same manner, until they had finished eight rounds. The participants made between 0 and 250 errors in this phase $(M=59.2)$.

Similarity judgment task After completing the learning phase, participants judged the similarity among images. They saw 24 pairs of unlabeled items and were asked to rate the visual similarity of the images by pressing a number between 1 and 7, with 1 being Not similar at all and 7 being Very similar. Four of the pairs shared a polysemous label, and two of the pairs shared a homonymous label.

The entire procedure lasted between 30 and $50 \mathrm{~min}$, depending on the time that it took participants to complete the practice stage.

Results

One participant was excluded because of previous participation in a related study; one because of failure to recall any of 
the control items on the retrieval-induced inhibition task, which prevented calculation of an inhibition score; and one for giving a rating of 7 to $80 \%$ of the items, including $100 \%$ of the experimental items. Three of the participants were excluded because their inhibitory skill score was more than 2.5 standard deviations from the mean. ${ }^{4}$ In order for inhibitory skill to influence the representations of linguistic units, participants must know those linguistic units. Therefore, we excluded all of the ratings of items for which participants provided an erroneous name in the last round of practice. In total, $4.9 \%$ of responses were excluded for this reason.

We tested whether inhibitory skill influences the perceived similarity of homonymous and polysemous words with a mixed-model regression, with subjects and items as random variables and Inhibitory Skill and Ambiguity Type, as well as their interaction, as fixed factors. The dependent measure was the similarity ratings, $z$-scored by participants. This yielded a main effect of ambiguity type, such that the referents of polysemous labels received higher similarity ratings $(\beta=0.97, t=3.33)$. Importantly, we found the predicted Inhibitory Skill $\times$ Ambiguity Type interaction $(t=2.15$; see Fig. 3, and see Appendix D for the full table of results). The interaction was due to the fact that, whereas inhibitory skill was negatively associated with similarity ratings for the homonymous items $(\beta=-0.22)$, it was positively associated with similarity ratings for the polysemous items $(\beta=0.25)$. Neither slope was significant on its own, though, most likely due to the small number of items.

The results of Experiment 3 paralleled those of Experiment 2. The fact that level of inhibitory skill led to different patterns of similarity ratings across homonyms and polysemous words even in Experiment 3 shows that the effect of inhibitory skill is not due to a correlation between inhibitory skill and another factor that influences the rating threshold or task interpretation, nor is it due to implicit labeling. For example, a correlation between inhibitory skill and greater likelihood of noticing the shared label, greater or lesser likelihood of relying on the shared label, or a different interpretation of what similarity means would have led to lower or higher ratings for both types of ambiguous words. As a further check, we examined whether inhibitory skill predicted responses to the filler items. As in Experiment 2, inhibitory skill did not influence the similarity ratings of filler items $(\beta=0.02, t<1)$.

Participants differed in how difficult it was for them to learn the labels. The numbers of errors on the homonymous terms ranged from 0 to $53(M=11.2, S D=9.6)$, and the numbers of errors on the polysemous terms ranged from 0 to $55(M=10.8, S D=9.6)$. To make sure that the interaction was not due to differences in learning, which might influence the strength and stability of the associations between the

\footnotetext{
${ }^{4}$ None of the participants in Experiment 2 had had a score that was more than $2.5 S D$ s from the mean.
}

labels and the objects, and therefore their representations, we tested whether inhibitory skill predicted the number of errors that participants made while learning the language. Inhibitory skill did not predict the number of errors on homonymous items, nor did it predict the number of errors on polysemous items (both $t \mathrm{~s}<1$, both $p \mathrm{~s}>0.5$ ).

The results of this experiment support the proposal that inhibitory skill can influence the representation of linguistic units. Specifically, they show that even very limited experience in processing ambiguous terms is sufficient to shape the meaning of those terms differently for people with different levels of inhibitory skill. The less that people are able to inhibit competing meanings when processing homonyms, the more they perceive the meanings as being similar, and the more that people can exercise executive control to activate related senses of polysemous terms, the more they perceive these senses as being similar.

\section{General discussion}

Taken together, the results of these three experiments converge in support of our claim that linguistic representations vary systematically from one person to another as a function of executive control. Although the first experiment showed this in the context of bilingualism, it was subject to an alternative interpretation. The second and third experiments demonstrated our claim within a language and ruled out the alternative interpretation. These results support the proposal that poorer executive control leads to greater coactivation of translation equivalents and the meanings of homonymous terms, and consequently, to greater perceived similarity of these coactivated concepts. In contrast, better executive control leads to higher activation of

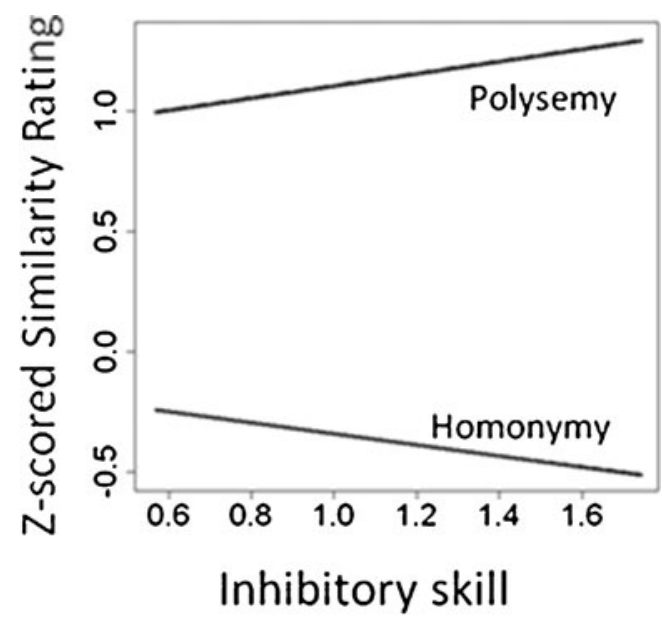

Fig. 3 Perceived similarity of the referents of ambiguous terms in Experiment 3, measured by participants' $z$-scored ratings of picture pairs as a function of inhibitory skill and type of ambiguity. See the Method section for details on how inhibitory skill was measured 
the meanings of polysemous terms, and consequently, to greater perceived similarity of their meanings.

There is controversy in the literature regarding the locus of the control mechanisms that govern cross-linguistic and intralinguistic inhibition. For example, whereas some postulate that the inhibitory mechanism is at least partially general in nature, operates top-down, and can inhibit an entire language (e.g., D. W. Green, 1998), others argue that it operates locally, inhibiting only competing words (e.g., Dijkstra \& van Heuven, 2002), and might even be automatic in nature (Colzato et al., 2008; Treccani et al., 2009). The retrievalinduced inhibition tasks used in Experiments 2 and 3 were based on local inhibition at the word level, and could be in line with all accounts, since despite the clear fit with Dijkstra and van Heuven's local-inhibition account, it is also possible that what is local inhibition during monolingual processing maps onto global inhibition at the bilingual processing level. At the same time, the working memory task used in Experiment 1 measured top-down, nonautomatic inhibition (Kane, Bleckley, Conway, \& Engle, 2001). The retrievalinduced inhibition task is sensitive to participants' goals (Smith \& Hunt, 2000), and therefore reflects top-down inhibition, as well. It therefore seems that the type of executive control that governs cross-linguistic and intralinguistic types of interference and that influences perceived similarity is at least partly of a controlled nature. At the same time, it is possible that differences in more bottom-up automatic inhibition also play a role in cross- and intralinguistic inhibition, and therefore lead to individual differences in meaning representation.

Our experiments focused on the influence of translation equivalents on one another and on the perceived similarity of the meanings of ambiguous terms. Yet, executive control plays an integral role in many aspects of language processing, and therefore could have additional effects. For example, executive control plays a role in processing figurative language, and in lexical retrieval in general (Anderson et al., 1994; Gernsbacher, Keysar, Robertson, \& Werner, 2001). It is therefore likely that it similarly influences the perceived similarity between other linguistic structures whose inhibition it governs during processing, such as the similarity between figurative expressions and their literal meaning, the perceived similarity between semantically related words, or even the similarity of phonological neighbors.

Our experiments also suggest parallels between monolingual and bilingual processing. It has often been asked whether the competition between translation equivalents is similar to the competition between words in the same language (e.g., Marian, Blumenfeld, \& Boukrina, 2008). Our results suggest that there are similarities, but that translation equivalents behave like different meanings of a homonym. Despite the similarity in meanings across translation equivalents, the meanings do not derive from one another, and need to be inhibited during processing. This leads to competition and inhibition similar to those that occur with homonymous meanings of words. It seems, then, that although speakers use similar processes within a language and across languages, they need to apply the processes differently. They enhance the activation of words of similar meanings within a language, but inhibit them across languages.

Our account can also be extended to the phenomenon of cross-linguistic interference in general. Although much research has looked at the roles of language history and of specific linguistic features in predicting cross-linguistic interference (e.g., Cook, 2003), individual differences in cognitive abilities are only starting to be taken into account. Considering the fact that cognitive skills are assumed to govern the inhibition of the language not in use, and that people vary greatly in their cognitive skills, individual differences in cognitive skills might explain some of the variability in cross-linguistic interference. The experience of using two or more languages enhances one's executive control (Bialystok \& Craik, 2010), yet there is great variability in executive control even among bilinguals. Experiment 1 showed that executive control influences the degree to which bilinguals think in a language-specific manner.

Executive control might similarly influence the degree to which bilinguals experience cross-linguistic interference at all linguistic levels - lexical, syntactic, phonological, and so on. Similarly to the way that translation equivalents need to be inhibited during processing, so do equivalent grammatical structures, phonological categories, and pronunciation rules. For example, French has shorter voice onset times than does English for initial $t$ s. Therefore, when producing words in English, French-English and English-French bilinguals need to inhibit the production rule in French, and vice versa. Executive control might determine the success of this inhibition, and therefore the degree to which bilinguals' production and perception are different in the different languages. Indeed, recent studies have supported this claim (Lev-Ari \& Peperkamp, 2013). At all linguistic levels, less successful inhibition could lead to greater coactivation, which could influence the degree to which the linguistic units influence one another and merge. Given that bilinguals are rarely fully balanced, the activation resting levels of their languages often differ. This suggests that the degrees to which a linguistic unit of the other language is activated in an inappropriate context can differ for bilinguals' different languages. Together, executive control and the difference in activation resting levels could explain and predict the degree of crosslinguistic influence and whether it would be symmetrical or asymmetrical.

The main contribution of our article has been to show that cognitive skills can influence linguistic representations. Understanding such variability in linguistic representations might help us understand language processing, both within a language and across the languages of bilinguals. It will thus 
help us understand systematic variability in the degree to which bilinguals' languages influence each other, and could have implications for communicative success among both bilinguals and monolinguals.
Author Note We thank Aluma Tessler Gould, Andrew McLeod, Kevin Lanham, and Kate Burke for technical help in conducting the experiments, and Sharon Perperkamp and Sayuri Hayakawa for commenting on previous drafts. This research was funded by National Science Foundation Grant No. BCS-0849034.

\section{Appendix A}

Table 1 Stimuli used in our picture similarity tasks

\begin{tabular}{|c|c|c|c|}
\hline Items & & $\begin{array}{l}\text { Language in which } \\
\text { label is shared }\end{array}$ & $\begin{array}{l}\text { Experiment(s) in } \\
\text { which it was used }\end{array}$ \\
\hline ארון Coffin; & ארון Wardrobe & Hebrew & 1 \\
\hline Ice cream cone; גביע & גביע ;Championship cup & Hebrew & 1 \\
\hline Ball; כדור & Bullet; כדור & Hebrew & 1 \\
\hline Bשת Bow; & קשת Arch & Hebrew & 1 \\
\hline קוביה Cube; & קוביה Die; & Hebrew & 1 \\
\hline קופסא Can of conserves & Phoebox; קופסא & Hebrew & 1 \\
\hline To drag; לגרור & To tow; לגרור & Hebrew & 1 \\
\hline לשאוב To draw water; & To vacuum; לשאוב & Hebrew & 1 \\
\hline Grenade; רימון & Pomegranate; רימון & Hebrew & 1 \\
\hline רוח Ghost; & רוח רind & Hebrew & 1 \\
\hline Bרט Bow & Film; סרט & Hebrew & 1 \\
\hline Necklace; שרשרת & Necklace; שרשרת & Hebrew & 1 \\
\hline תנור Oven; & תנור Space heater; & Hebrew & 1 \\
\hline Hבע Hair dye & צaint; צבע & Hebrew & 1 \\
\hline Arrow; חץ & חי חץ Dart & Hebrew & 1 \\
\hline בר Bar; & Bar; הטיף & English & $1 \& 2$ \\
\hline Bat; אלה & Batעלק; & English & $1 \& 2$ \\
\hline מאוורר;Fan & Fanמאורר; & English & $1 \& 2$ \\
\hline כוסות; Glasses & Glasses ; משקפיים & English & $1 \& 2$ \\
\hline Key; מפתח & מקש ; Key & English & $1 \& 2$ \\
\hline Nail; מסמר & Nail; ציפורן & English & $1 \& 2$ \\
\hline Pipe ; מקטרת & צipe; צינור & English & $1 \& 2$ \\
\hline To play; לנגן & To play; לשחק & English & $1 \& 2$ \\
\hline Pool; בריכה & Pool; ביליארד & English & $1 \& 2$ \\
\hline Table; שולחן & טבלא Table; & English & $1 \& 2$ \\
\hline תא מטען ; Trunk & גזע Trunk & English & $1 \& 2$ \\
\hline Bag & $\mathrm{Bag}$ & English & 2 \\
\hline Bed & Bed & English & 2 \\
\hline Card & Card & English & 2 \\
\hline Chips & Chips & English & 2 \\
\hline Gum & Gum & English & 2 \\
\hline Shell & Shell & English & 2 \\
\hline Tape & Tape & English & 2 \\
\hline Wall & Wall & English & 2 \\
\hline Arrow & Arrow & English & 2 \\
\hline
\end{tabular}


Appendix B

Table 2 Stimuli used in Experiment 3

Object
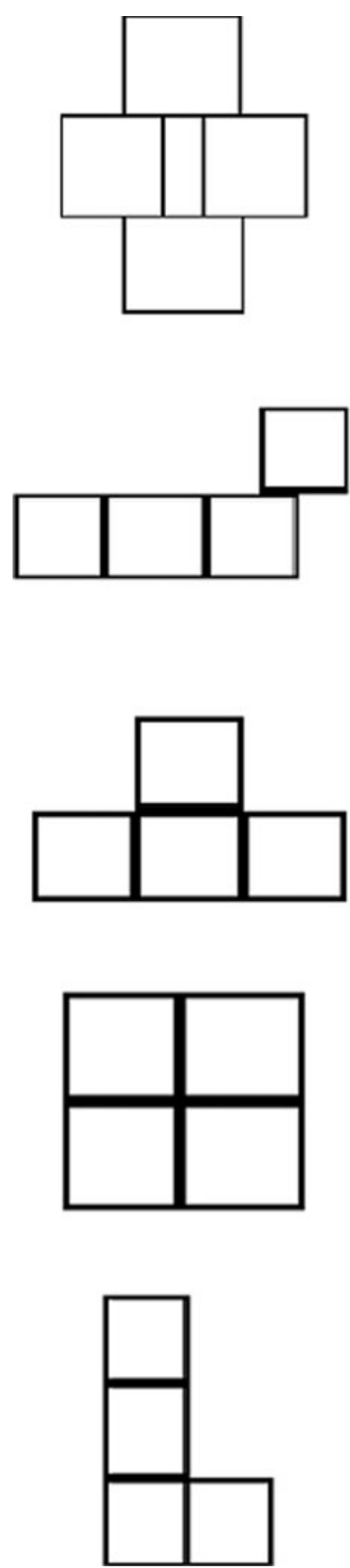

Label

MORK/ELD

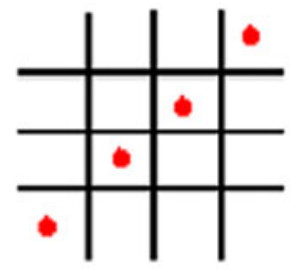

ELD/BROUP

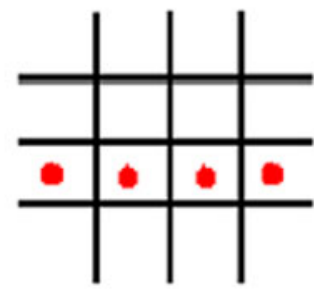

BROUP/ELD

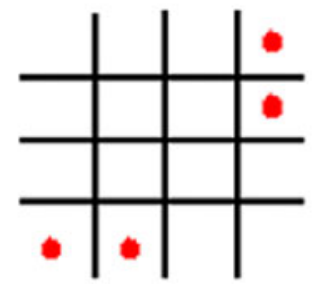

GEMBER/ZEEK

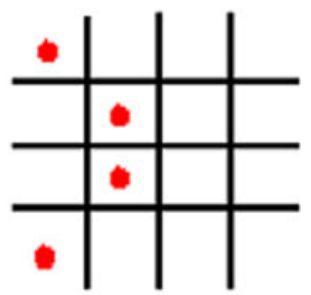

ZEEK/GEMBER

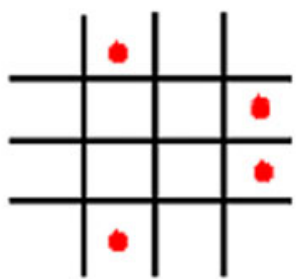

Label

PLAVE/JASE

JASE/PLAVE

HODE/DIFE

DIFE/HODE

DIFE/MONSH 
Table 2 (Continued)

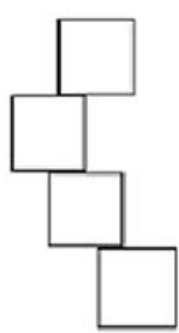

ELD/MORK

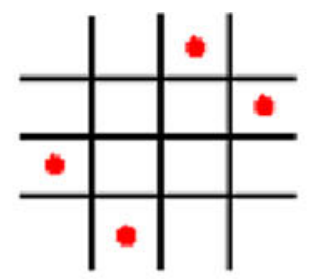

MONSH/DIFE

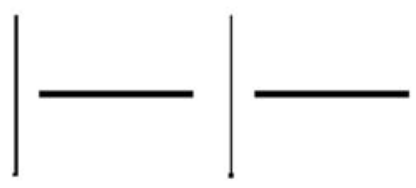

PLAVE/RAND

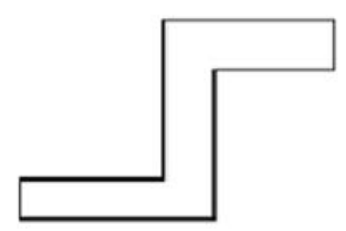

HOUVE/NACT

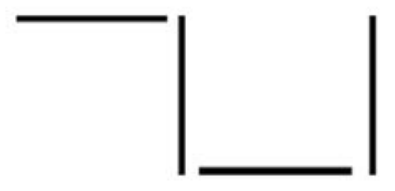

RAND/PLAVE

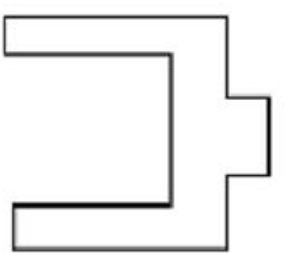

ZEEK/STAME

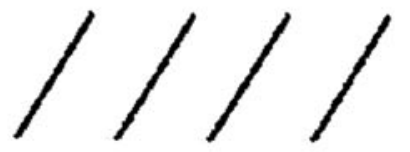

VART/SARTY

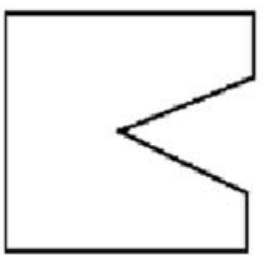

NACT/HOUVE

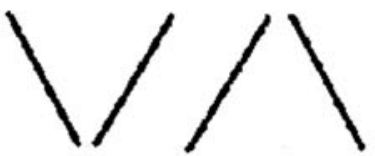

SARTY/VART

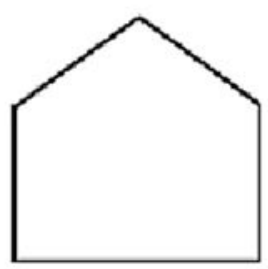

NACT/TOINT

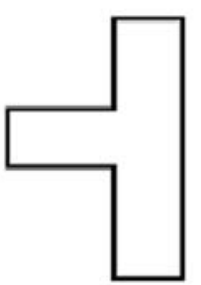

STAME/ZEEK

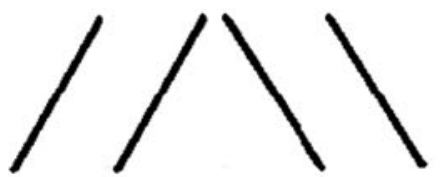

SARTY/PORD

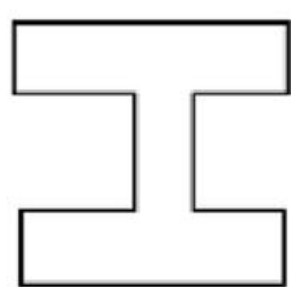

TOINT/NACT

PORD/SARTY 


\section{Appendix C}

Table 3 Full table of results for Experiment 2

\begin{tabular}{llll}
\hline & Estimate & Std. Error & $t$ Value \\
\hline Intercept & -0.3233 & 0.2116 & -1.528 \\
Type (poly) & 0.2709 & 0.19 & 1.426 \\
Inhibition & 0.324 & 0.2843 & 1.139 \\
Inhibition $\times$ Type (poly) & 0.6188 & 0.2553 & 2.424 \\
\hline
\end{tabular}

\section{Appendix D}

Table 4 Full table of results for Experiment 3

\begin{tabular}{llll}
\hline & Estimate & Std. Error & $t$ Value \\
\hline Intercept & -0.1177 & 0.2483 & -0.474 \\
Type (poly) & 0.973 & 0.2919 & 3.333 \\
Inhibition & -0.2222 & 0.1912 & -1.162 \\
Inhibition $\times$ Type (poly) & 0.4749 & 0.221 & 2.149 \\
\hline
\end{tabular}

\section{References}

Anderson, M. C., Bjork, R. A., \& Bjork, E. L. (1994). Remembering can cause forgetting: Retrieval dynamics in long-term memory. Journal of Experimental Psychology: Learning, Memory, and Cognition, 20, 1063-1087. doi:10.1037/0278-7393.20.5.1063

Aslan, A., \& Bäuml, K.-H. (2011). Individual differences in working memory capacity predict retrieval-induced forgetting. Journal of Experimental Psychology: Learning, Memory, and Cognition, 37, 264-269. doi:10.1037/a0021324

Baayen, R. H. (2008). Analyzing linguistic data: A practical introduction to statistics using $R$. Cambridge, UK: Cambridge University Press.

Beretta, A., Fiorentino, R., \& Poeppel, D. (2005). The effects of homonymy and polysemy on lexical access: An MEG study. Cognitive Brain Research, 24, 57-65.

Bialystok, E., \& Craik, F. I. M. (2010). Cognitive and linguistic processing in the bilingual mind. Current Directions in Psychological Science, 19, 19-23. doi:10.1177/0963721409358571

Cantor, J., \& Engle, R. W. (1993). Working-memory capacity as longterm memory activation: An individual differences approach. Journal of Experiment Psychology: Learning, Memory and Cognition, 19, 1101-1114.

Collins, A. M., \& Loftus, E. F. (1975). A spreading activation theory of semantic processing. Psychological Review, 82, 407-428. doi:10. 1037/0033-295X.82.6.407

Colzato, L. S., Bajo, M. T., van den Wildenberg, W., Paolieri, D., Nieuwenhuis, S. T., La Heij, W., \& Hommel, B. (2008). How does bilingualism improve executive control? A comparison of active and reactive inhibition mechanisms. Journal of Experimental Psychology: Learning, Memory, and Cognition, 34, 302-312.
Cook, V. (Ed.). (2003). Effects of the second language on the first. Clevedon, UK: Multilingual Matters.

Costa, A., Hernández, M., \& Sebastián-Gallés, N. (2008). Bilingualism aids conflict resolution: Evidence from the ANT task. Cognition, 106, 59-86. doi:10.1016/j.cognition.2006.12.013

Degani, T., Prior, A., \& Tokowicz, N. (2011). Bidirectional transfer: The effects of sharing a translation. European Journal of Cognitive Psychology, 23, 18-28.

Dijkstra, T., \& van Heuven, W. J. B. (2002). The architecture of the bilingual word recognition system: From identification to decision. Bilingualism: Language and Cognition, 5, 175-197.

Elston-Güttler, K., \& Friederici, A. (2005). Native and L2 processing of homonyms in sentential context. Journal of Memory and Language, 52, 256-283.

Elston-Güttler, K. E., \& Williams, J. N. (2008). First language polysemy affects second language meaning interpretation: Evidence for activation of first language concepts during second language reading. Second Language Research, 24(2), 167-187.

Festman, J., Rodriguez-Fornells, A., \& Münte, T. F. (2010). Individual differences in control of language interference in late bilinguals are mainly related to general executive abilities. Behavioral and Brain Functions, 6, 5. doi:10.1186/1744-9081-6-5

Finkbeiner, M., Forster, K., Nicol, J., \& Nakamura, K. (2004). The role of polysemy in masked semantic and translation priming. Journal of Memory and Language, 51, 1-22.

Frazier, L., \& Rayner, K. (1990). Taking on semantic commitments: Processing multiple meanings vs. multiple senses. Journal of Memory and Language, 29, 181-200.

Gadsby, N., Arnott, W. L., \& Copland, D. A. (2008). An investigation of working memory influences on lexical ambiguity resolution. Neuropsychology, 22, 209-216.

Gernsbacher, M. A., \& Faust, M. E. (1991). The mechanism of suppression: A component of general comprehension skill. Journal of Experimental Psychology: Learning, Memory, and Cognition, 17, 245-262. doi:10.1037/0278-7393.17.2.245

Gernsbacher, M. A., Keysar, B., Robertson, R. R. W., \& Werner, N. K. (2001). The role of suppression and enhancement in understanding metaphors. Journal of Memory and Language, 45, 433-450.

Gernsbacher, M. A., \& Robertson, R. R. W. (1995). Reading skill and suppression revisited. Psychological Science, 6, 165-169.

Gernsbacher, M. A., Varner, K. R., \& Faust, M. E. (1990). Investigating differences in general comprehension skill. Journal of Experimental Psychology: Learning, Memory, and Cognition, 16, 430-445. doi: $10.1037 / 0278-7393.16 .3 .430$

Giora, R. (2003). On our mind: Salience, context, and figurative language. New York, NY: Oxford University Press.

Gollan, T. H., Sandoval, T., \& Salmon, D. P. (2011). Cross-language intrusion errors in aging bilinguals reveal the link between executive control and language selection. Psychological Science, 22, $1155-1165$.

Green, D. W. (1998). Mental control of the bilingual lexicosemantic system. Bilingualism: Language and Cognition, 1, 67-81.

Green, C. S., \& Bavelier, D. (2003). Action video game modifies visual selective attention. Nature, 423, 534-537. doi:10.1038/nature01647

Jaeger, T. F. (2008). Categorical data analysis: Away from ANOVAs (transformation or not) and towards logit mixed models. Journal of Memory and Language, 59, 434-446. doi:10.1016/j.jml.2007.11.007

Jiang, N. (2000). Lexical representation and development in a second language. Applied Linguistics, 21, 47-77.

Kane, M. J., Bleckley, M. K., Conway, A. R. A., \& Engle, R. W. (2001). A controlled-attention view of working-memory capacity. Journal of Experimental Psychology. General, 130, 169-183. doi:10.1037/ 0096-3445.130.2.169

Kane, M. J., Conway, A. R. A., Hambrick, D. Z., \& Engle, R. W. (2007). Variation in working memory capacity as variation in executive attention and control. In A. R. A. Conway, C. Jarrold, M. J. Kane, 
A. Miyake, \& J. N. Towse (Eds.), Variation in working memory (pp. 21-48). New York, NY: Oxford University Press.

Kane, M. J., \& Engle, R. W. (2003). Working memory capacity and the control of attention: The contributions of goal neglect, response competition, and task set to Stroop interference. Journal of Experimental Psychology. General, 132, 47-70. doi:10.1037/0096-3445. 132.1.47

Kelin, D. E., \& Murphy, G. L. (2001). The representation of polysemous words. Journal of Memory and Language, 45, 259-282.

Klepousniotou, E., \& Baum, S. R. (2007). Disambiguating the ambiguity advantage effect in word recognition: An advantage for polysemous but not homonymous words. Journal of Neurolinguistics, 20, $1-24$.

Klepousniotou, E., Pike, G. B., Steinhauer, K., \& Gracco, V. (2012). Not all ambiguous words are created equal: An EEG investigation of homonymy and polysemy. Brain and Language, 123, 11-21.

Klepousniotou, E., Titone, B., \& Romero, C. (2008). Making sense of word senses: The comprehension of polysemy depends on sense overlap. Journal of Experimental Psychology: Learning, Memory, and Cognition, 34, 1534-1543. doi:10.1037/a0013012

La Heij, W. (1988). Components of Stroop-like interference in picture naming. Memory \& Cognition, 16, 400-410. doi:10.3758/BF03214220

Lev-Ari, S., \& Peperkamp, S. (2013). Low inhibitory skill leads to nonnative perception and production in bilinguals' native language. Journal of Phonetics, 41, 320-331.

Linck, J. A., Schwieter, J. W., \& Sunderman, G. (2012). Inhibitory control predicts language switching performance in trilingual speech production. Bilingualism: Language and Cognition, 15, 651-662. doi:10.1017/S136672891100054X

Marian, V., Blumenfeld, H., \& Boukrina, O. (2008). Sensitivity to phonological similarity within and across languages: A native/nonnative asymmetry in bilinguals. Journal of Psycholinguistic Research, 37, 141-170.
Meuter, R. F. I., \& Allport, A. (1999). Bilingual language switching in naming: Asymmetrical costs of language selection. Journal of Memory and Language, 40, 25-40.

Odlin, T. (1989). Language transfer. New York, NY: Cambridge University Press.

Pylkkãnen, L., Llinás, R., \& Murphy, G. (2006). The representation of polysemy: MEG evidence. Journal of Cognitive Neuroscience, 18 , 97-109.

Rodd, J., Gaskell, G., \& Marslen-Wilson, W. (2002). Making sense of semantic ambiguity: Semantic competition in lexical access. Journal of Memory and Language, 46, 245-266.

Rosen, V. M., \& Engle, R. W. (1998). Working memory capacity and suppression. Journal of Memory and Language, 39, 418-436.

Smith, R. E., \& Hunt, R. R. (2000). The influence of distinctive processing on retrieval-induced forgetting. Memory \& Cognition, $28,503-508$.

Spivey, M. J., \& Marian, V. (1999). Cross talk between native and second languages: Partial activation of an irrelevant lexicon. Psychological Science, 10, 281-284.

Treccani, B., Argyri, E., Sorace, A., \& Della Sala, S. (2009). Spatial negative priming in bilingualism. Psychonomic Bulletin \& Review, 16, 320-327.

Tuggy, D. (1993). Ambiguity, polysemy, and vagueness. Cognitive Linguistics, 4, 3.273-290.

Unsworth, N., Heitz, R. P., Schrock, J. C., \& Engle, R. W. (2005). An automated version of the operation span task. Behavior Research Methods, 37, 498-505.

Veling, H., \& van Knippenberg, A. (2004). Remembering can cause inhibition: Retrieval-induced inhibition as cue independent process. Journal of Experimental Psychology: Learning, Memory, and Cognition, 30, 315-318. doi:10.1037/0278-7393.30.2.315

Wu, Y. J., \& Thierry, G. (2010). Chinese-English bilinguals reading English hear Chinese. Journal of Neuroscience, 30, 7646-7651. 